\title{
EFFICACY OF PLATELET RICH FIBRIN VERSUS GELATIN SPONGE OR TRANEXAMIC ACID ON HEMOSTASIS AND WOUND HEALING FOLLOWING TOOTH EXTRACTION IN PATIENTS ON ANTICOAGULANT THERAPY
}

\author{
Noha Ahmed Mansour * and Islam Mohammed Ateia **
}

\begin{abstract}
Objectives: Management of patients who are maintained on oral anticoagulant therapy represents a major challenge in the dental practice due to the significant risk of postoperative hemorrhagic complications and subsequent delayed wound healing. This study was performed to evaluate the local efficacy of Platelet Rich Fibrin (PRF), gelatin sponge and tranexamic acid following dental extraction in patients taking Warfarin.
\end{abstract}

Methods: Forty-five patients having an International Normalized Ratio (INR) $<3.5$ underwent atraumatic extraction of 57 teeth under local anesthesia. Patients were allocated equally into 3 groups. Group A: the extraction sockets were packed with PRF, group B: the extraction sockets were packed with gelatin sponge, group $\mathrm{C}$ : a gauze soaked with tranexamic acid pressed over socket for 30 minutes. Immediate and delayed postoperative bleeding, socket healing and postoperative pain were assessed at different times of follow up.

Results: PRF significantly reduced postoperative bleeding after 5-, 30- and 60-minutes post extraction. No significant difference at 1 or 3 days postoperatively. Patients in group A recorded minimal postoperative pain and accelerated healing.

Conclusions: PRF has significant antihemorrhagic properties, increases tissue healing and wound closure and decrease postoperative pain. It is a promising autogenous, low cost, local hemostatic modality that can be used safely after dental extraction for patients under anticoagulant therapy.

KEYWORDS: Anticoagulant therapy; Platelet rich fibrin; gelatin sponge; tranexamic acid; Dental extraction.

* Lecturer of Oral Surgery, Faculty of Dentistry, Mansoura University, Mansoura, Egypt.

** Lecturer of Oral Medicine and Periodontology. Faculty of Dentistry, Mansoura University, Mansoura, Egypt. 


\section{INTRODUCTION}

The proper approach to dental extractions in patients on oral anticoagulant therapy (OAT) remains a matter of debate focused on the balance between the risk of thromboembolic events and bleeding complications. ${ }^{(1)}$ Antiplatelet and anticoagulants are usually used to manage cardiac or vascular disorders, including pulmonary embolism, ischemic heart disease, deep venous thrombosis, atrial fibrillation, cardiac valvular disease, prosthetic heart valves, and cerebrovascular accident. ${ }^{(2,3)}$ Warfarin which is a vitamin $\mathrm{K}$ antagonist, is one of the most frequently prescribed oral anticoagulants. ${ }^{(4,5)}$

The activity of anticoagulants is monitored by the international normalized ratio (INR) which must be measured prior to dental procedures. Normal INR level range between 0.9 and 1 for individuals who are not on anticoagulant medication. A higher therapeutic range of 2-3.5 is generally effective for patients taking warfarin. It differs according to the patient condition. ${ }^{(6,7)}$

There is no generally admitted strategy for preventing bleeding with minor oral surgery in patients on anticoagulant medications. It was common to be withdrawn or altered before elective surgery due to the fear of bleeding. However, any interruption of blood thinning therapy increases the risk of thromboembolic events, which can be life-threatening. ${ }^{(7,8)}$

An increasing number of authors claim that tooth extraction in anticoagulated patients within the therapeutic International Normalized Ratio up to 4.0 can be safely done without altering OAT regimen with the help of local hemostatic measures which stabilize or enhance clot formation at the surgical site. ${ }^{(9-12)}$

Numerous local hemostatic agents have been used in oral and maxillofacial surgery including suturing, gel foam, tranexamic acid, oxidized cellulose, fibrin glue and cyanoacrylate glue.(13-17) The ideal hemostatic agent depends on its effective- ness, cost, and convenience. Despite the reported efficacy of such agents, the introduction of newer and more efficient agents is encouraged.

Platelet-rich fibrin (PRF) is an autogenous material derived from a person's own blood; it was developed as a second-generation platelet concentrate without the addition of anticoagulants at lower centrifugation speeds. ${ }^{(18)}$ The PRF clot serves as a three-dimensional fibrin pathway, it is considered a reservoir of natural growth factors and cytokines, which may be released slowly to play a crucial role in the repair of soft and hard tissues. Among the identified growth factors contained in PRF are Insulin like Growth Factor-1(IGF-1), Epidermal Growth Factor (EGF), Vascular Endothelial Growth Factor (VEGF) Transforming Growth Factor- $\beta$ (TGF- $\beta$ ), and Platelet-Derived Growth Factors (PDGFs). ${ }^{(19)}$

PRF has gained significant interest in the dental society because of its regenerative properties and its ability to promote wound healing. ${ }^{(20)}$ It has been used to improve the repair process in post-extraction sockets, sinus lifts, periodontal bone defects, and periodontal plastic surgeries. ${ }^{(21-23)}$ The aim of this study was to assess the hemostatic efficacy of platelet rich fibrin versus tranexamic acid dressing or gelatin sponge placed in bony sockets in patients receiving oral anticoagulant therapy and also to evaluate the surgical healing outcome following dental extractions.

\section{PATIENTS AND METHODS}

This study was conducted on forty-five patients receiving oral anticoagulant therapy (OAT) requiring dental extraction, patients were referred to Oral and Maxillofacial surgery department, Faculty of Dentistry, Mansoura University.

The study followed the Declaration of Helsinki on medical protocol and ethics and was approved by the Ethical Review Board of Mansoura University. All patients were informed about the risks and 
benefits of the procedure, and they provided written informed consents for the treatment plan.

\section{Inclusion criteria}

- Patients included in study were either Gender (Male or female), receiving Warfarin (OAT), requiring simple dental extraction of non-restorable teeth.

\section{Exclusion criteria ${ }^{(24,25)}$}

- Teeth with periapical pathosis.

- Patients with uncontrolled systemic diseases such as uncontrolled diabetic or hypertensive patients and patients with liver or renal diseases.

- Patients with INR exceed (>3.5) due to lack of proper local hemostatic agent action.

- Patients with immunosuppressive diseases.

\section{Patients grouping \& materials}

After atraumatic extraction of the affected teeth, patients divided equally into three groups according to the used local hemostatic measure.

Group A: the extraction sockets were packed with PRF clot prepared from the patient own blood (fig.1a)

Group B: the extraction sockets were packed with absorbable sterile gelatin sponge *, sized $(10 \times 10 \times 10 \mathrm{~mm})$. (fig.1b)

Group C: a gauze pad soaked in tranexamic acid $^{* *}(500 \mathrm{mg} / 5 \mathrm{ml})$, antifibrinolytic agent which inhibits the activation of plasminogen to plasmin, was applied to the surgical alveolus under biting pressure for 30 minutes. (fig.1c)

\section{Preoperative phase}

- Demographic data, presenting name, age, chief complain, medical history and dental history

* Cutanplast, Mascia Brunelli, Millano-Italy.

** Tranexamic Acid, Amoun Pharmaceutical Co- Egypt.

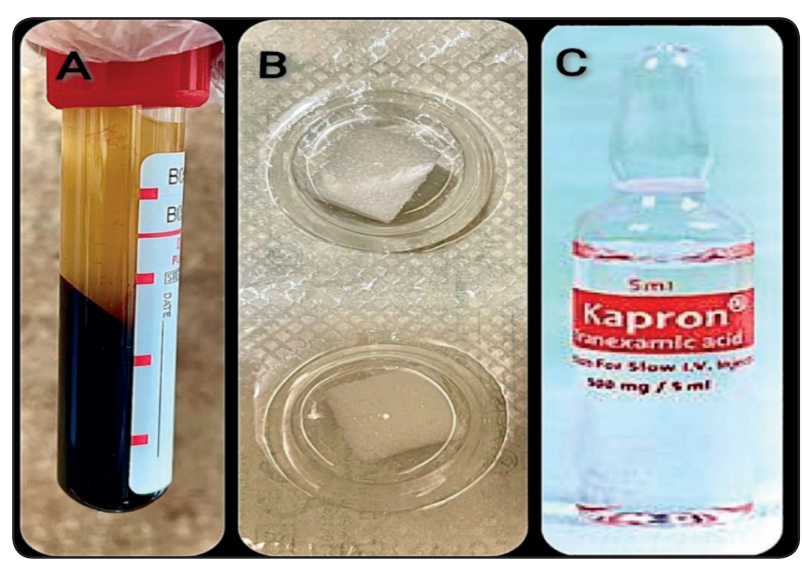

Fig. (1): Local hemostatitics applied to extraction sockets for the three groups of patients

A. Platelet rich fibrin clot formed after blood centrifugation.

B. Resorpable sterilized gelatin sponge.

C. Tranexamic acid.

were collected from patients. Clinical extra oral and intra oral examination was done to examine the difficulty of tooth extraction and assess the presence of infection.

- Preoperative laboratory investigations were carried out for all patients including complete blood picture, Bleeding time (BT), Prothrombin time (PT), International Normalized Ratio (INR(, partial thromboplastin time (PPT).

- Preoperative periapical x-ray was taken to exclude the teeth with periapical pathosis for all patients.

- Prophylactic antibiotic was prescribed for patients by giving oral antibiotic $2 \mathrm{gm}$ Amoxicillin two hours before dental extraction as prophylactic therapy. The regimen was recommended by the American Heart Association for prophylactic antibiotic coverage against bacterial endocarditis. ${ }^{(26)}$

- All patients were motivated to maintain proper oral hygiene by using chlorhexidine mouth wash. 


\section{Operative phase}

Aseptic surgical technique was followed throughout the whole procedures. All patients were maintained on their anti-coagulation treatment without discontinuing or modifying the dose. Local anesthesia was obtained by infiltration or nerve block technique, according to the affected tooth, using 2\% mepivacaine hydrochloride with 1:20,000 levonordefrin (Mepecaine; GlaxoSmithKline, Cairo). Dental extractions were then performed as atraumatic as possible, using extraction forceps and/ or elevators when needed.

According to the local haemostatic agent to be used, patients were allocated into one of the three groups: Group (A) 10 milliliter of blood was collected from the patient in disposable syringe and divided into two equal sterile glass tubes without anticoagulants. These tubes immediately centrifuged on a table-top centrifuge at a rate of $3000 \mathrm{rpm}$ for
12 minutes. After centrifugation, three layers are obtained in the test tube. PFR clot is present in the middle of the tube, just between the red blood cells at the bottom and acellular plasma at the top. PRF clot is then removed with sterile tweezers and separated from the underlying RBC layer using scissors. It was immediately packed into post-extraction socket (fig. 2). Group (B) absorbable sterile gelatin sponge was placed into the extraction socket. Group (C) gauze pad soaked with $2 \mathrm{ml}$ of tranexamic acid $(500 \mathrm{mg} / 5 \mathrm{ml})$ was applied to the surgical alveolus under biting pressure.

\section{Postoperative phase}

The patient was asked to apply a gentle biting pressure on a gauze pad placed over the socket for about 90 minutes, all groups were monitored for postoperative bleeding. The patient was not allowed to leave the clinic unless bleeding from the

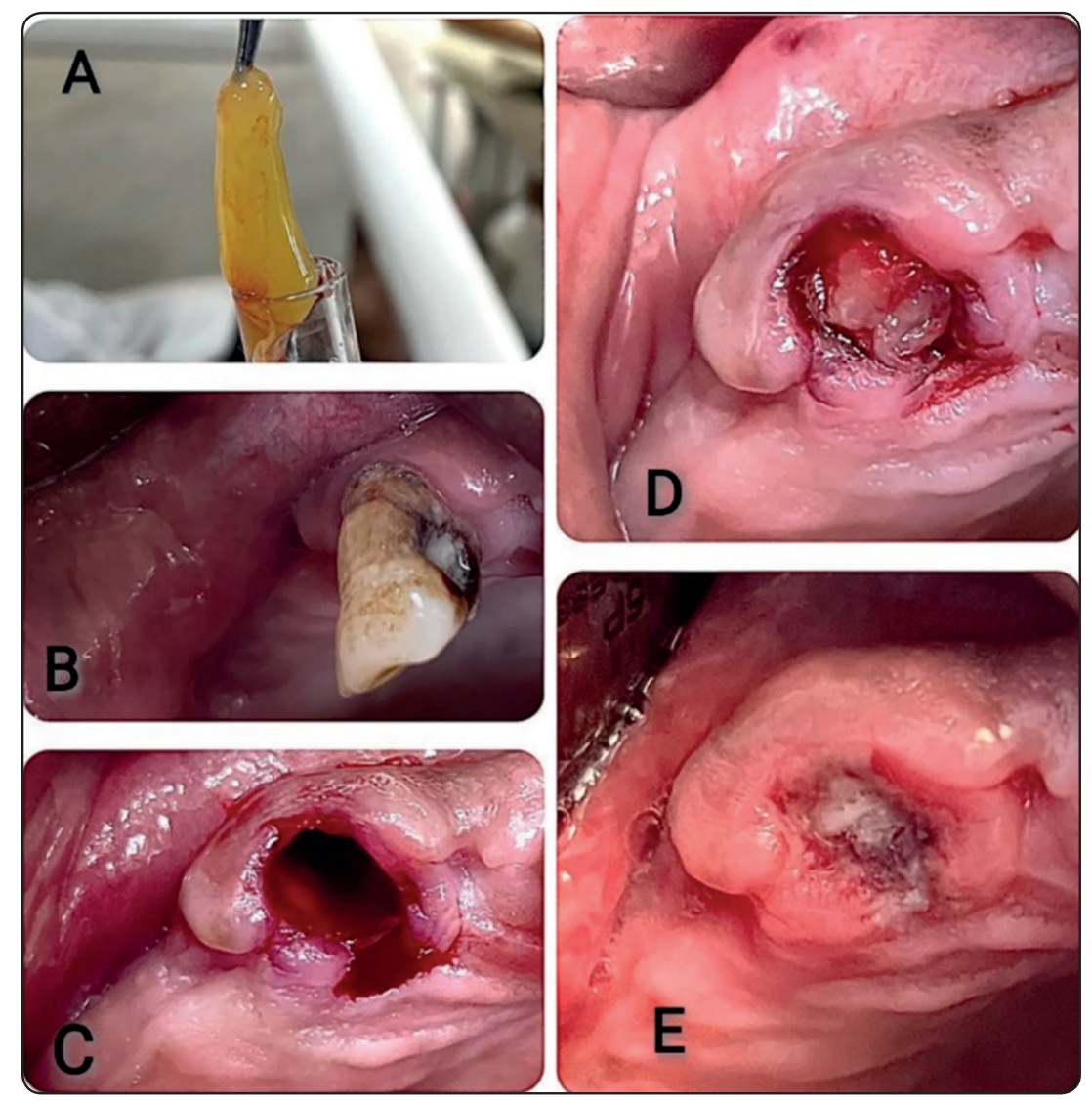

Fig. (2): Photographs showing application of PRF to dental socket:

A. PRF clot retrieved from the tube after blood centrifugation by a sterilized tweezer.

B. Unrestorable maxillary canine.

C. Dental socket after extraction.

D. PRF packed into extraction socket immediately after extraction.

E. Post-operative photograph of the extraction site after 1 day. 
extraction sites was fully controlled. Patients were given the postoperative instructions that include:

- Avoid using any mouth wash for 24 hours.

- Avoid smoking, sucking and disturbing the socket with tongue, finger manipulation or any foreign object.

- Avoid hot fluids and hard foods for the first three days especially on the side of the extraction.

- Paracetamol $500 \mathrm{mg}$ was the analgesic of choice in case of pain, the patients were advised to avoid Aspirin and Non-steroidal anti-inflammatory drugs.

- All patients were asked to be in contact to report any bleeding complications after extraction.

\section{Postoperative assessment}

\section{I-Bleeding}

All patients were examined postoperatively for bleeding after 5 minutes, 30 minutes, 60 minutes, 1 day and 3 days postoperatively using the following scale:(27)

Grade 0: No bleeding or very low.

Grade 1: Low (slight oozing of blood stops by itself or after applying pressure).

Grade 2: Normal (significant bleeding).

Grade 3: High Bleeding (occurs after formation of clot).

Grade 4: Excessive bleeding that could not be controlled by local hemostatic agents or stitches)

\section{II-Healing}

Outcome of healing was evaluated at 7th day after extraction according to further classification used by Ishihama et al: (28)

Grade 0: Patients showed deep or sever infection.

Grade 1: Patients showed dry socket infection.
Grade 2: Patients showed delay of granulation.

Grade 3: Patients showed delayed healing without infection.

Grade 4: Patients showed normal healing.

\section{III-Postoperative Pain}

Pain was evaluated using categorical verbal rating scale (VRS) ${ }^{(29)}$ on the first, third and seventhdays post-extraction.

No pain=0, Mild pain=1, Moderate pain=2, Severe pain $=3$, Extreme pain $=4$

\section{Statistical analysis}

The Statistical Package of Social Science (SPSS) program for Windows (Standard version 21) was used for analysis of the recorded data. Qualitative data were described in terms of number and percent. Continuous variables were presented as mean \pm SD (standard deviation) for normally distributed data. The three groups were compared with F-test One Way ANOVA test for parametrical data or chi square test for categorial non parametrical data. Ficher's exact test was used to verify significant association. The threshold of significance is fixed at 5\% level for all the statistical tests, considering the results significant only when $\mathrm{p} \leq 0.05$.

\section{RESULTS}

Forty-five patients, 26 males (57.8\%) and 19 females $(42.2 \%)$, included in this study underwent simple extraction of 57 teeth $(42.1 \%$ anterior teeth, $57.9 \%$ posterior teeth). Their ages were between 31 and 75 years with a of mean 53.2 years. All patients were using warfarin therapy due to: cardiac valvular disease (16 patients, $35.6 \%$ ), prosthetic heart valve (13 patients, 28.9\%), atrial fibrillation (11 patients, $24.4 \%$ ), or cerebrovascular accident (5 patients, $11.1 \%)$. Patients divided equally into three groups, 15 in each group. The INR of patients ranged between 1.4 and 3.3 (with a mean of 2.36). 
Clinical characteristics of patients in each group and causes for dental extraction were shown in table (1). No statistically significant difference was found between groups as regard sex, age, INR level, bleeding time, or prothrombin time.

\section{1) Postoperative Bleeding}

Table 2 demonstrates the postoperative bleeding grades recorded for the patients in all groups at different times of follow up. Bleeding could be controlled for all studied extraction sockets, no patient recorded grade 2,3 or 4 on bleeding scale. No bleeding was noted after 3 days post-extraction.

By Comparing all groups, the association between variables was statistically significant after 5 minutes $(\mathrm{p}=0.04), 30$ minutes $(\mathrm{p}=0.02)$, and 60 minutes $(\mathrm{p}=0.02)$. No significant association was found after 1 day or 3 days between groups.
By companying each two groups, there was a significant difference between group A and group $\mathrm{C}$ after 5 minutes, 30 minutes and 60 minutes (p2 $=0.02,0.008,0.008$ respectively). A significant difference between group A and group B was recorded after 60 minutes $(\mathrm{p} 1=0.03)$. However, no significant difference between group B and group C was recorded at different times ( $\mathrm{p} 3=0.17,0.33,0.73)$.

\section{2) Healing}

As regard socket healing evaluation after 7 days, there was no incidence of postoperative infection or dry socket in all patients. $95 \%$ of patients in PRF group, $38.9 \%$ in gelatin sponge group and $57.9 \%$ in tranexamic group showed normal healing (grade 4). By Comparing all groups, the association between variables was statistically significant $(\mathrm{p}=.008)$. PRF reduced the incidence of delayed healing in comparison to group B and group $\mathrm{C}(\mathrm{p} 1=.001$, $\mathrm{p} 2=.02)$ as shown in table (3).

TABLE (1): Clinical characteristics of the patients for each studied group.

\begin{tabular}{|c|c|c|c|c|}
\hline Characteristics & Group A & Group B & Group C & Test of significance \\
\hline Gender (male/ female), $\mathrm{n}$ & $9 / 6$ & $8 / 7$ & $9 / 6$ & $\begin{array}{c}\chi^{2}=0.18 \\
\mathrm{p}=.9\end{array}$ \\
\hline Age, mean \pm SD (years) & $52.9 \pm 11.3$ & $55.3 \pm 10.8$ & $51.4 \pm 11.1$ & $\begin{array}{c}\mathrm{F}=0.48 \\
\mathrm{P}=.6\end{array}$ \\
\hline INR, mean \pm SD & $2.55 \pm 0.56$ & $2.16 \pm 0.44$ & $2.36 \pm 0.42$ & $\begin{array}{c}\mathrm{F}=2.3 \\
\mathrm{P}=.1\end{array}$ \\
\hline $\mathrm{BT}$, mean $\pm \mathrm{SD}$ & $2.87 \pm 0.76$ & $3.14 \pm 1.08$ & $2.7 \pm 0.9$ & $\begin{array}{c}\mathrm{F}=0.86 \\
\mathrm{P}=.4\end{array}$ \\
\hline $\mathrm{PT}$, mean $\pm \mathrm{SD}$ & $16.54 \pm 3.9$ & $16.68 \pm 5.3$ & $16.33 \pm 4.02$ & $\begin{array}{c}\mathrm{F}=0.03 \\
\mathrm{P}=.96\end{array}$ \\
\hline $\begin{array}{l}\text { No. of extracted teeth } \\
\text { Anterior teeth } \\
\text { Posterior teeth }\end{array}$ & $\begin{array}{ll} & 20 \\
8 & (40 \%) \\
12 & (60 \%)\end{array}$ & $\begin{array}{lc} & 18 \\
7 & (38.9 \%) \\
11 & (61.1 \%)\end{array}$ & $\begin{array}{cc} & 19 \\
9 & (47.4 \%) \\
10 & (52.6 \%)\end{array}$ & $\begin{array}{c}\chi^{2}=2.8 \\
\mathrm{p}=.6\end{array}$ \\
\hline $\begin{array}{l}\text { Causes for extraction, } \mathrm{n} \\
\text { periodontal disease } \\
\text { deep caries } \\
\text { remaining root }\end{array}$ & $\begin{array}{l}7(35 \%) \\
8(40 \%) \\
5(25 \%)\end{array}$ & $\begin{array}{l}5(27.8 \%) \\
7(38.9 \%) \\
6(33.3 \%)\end{array}$ & $\begin{array}{l}6(31.6 \%) \\
4(21 \%) \\
9(47.4 \%)\end{array}$ & $\begin{array}{c}\chi^{2}=0.33 \\
p=.8\end{array}$ \\
\hline
\end{tabular}

INR - International normalized ratio; BT-bleeding time; PT-prothrombin time; SD - standard deviation; group A - patients with PRF used for local hemostasis; group B - patients with absorbable gelatin sponge used for local hemostasis; group $C$ - patients with tranexamic acid used for local hemostasis; $F$-ANOVA coefficient; $\chi 2$ - chi square test; p-significant at $\leq 0.05$ 
TABLE (2): Postoperative bleeding grades at different times for the three groups.

\begin{tabular}{|c|c|c|c|c|c|}
\hline \multirow[t]{2}{*}{ Bleeding scale } & \multicolumn{5}{|c|}{ Post operative bleeding (n /\%) } \\
\hline & 5 minutes & 30 minutes & 60 minutes & 1 day & 3 days \\
\hline \multicolumn{6}{|l|}{ Group A $(n=20)$} \\
\hline G0 & $12(60 \%)$ & $17(85 \%)$ & $19(95 \%)$ & $20(100 \%)$ & $20(100 \%)$ \\
\hline G1 & $8(40 \%)$ & $3(15 \%)$ & $1 \quad(5 \%)$ & 0 & 0 \\
\hline G2 & 0 & 0 & 0 & 0 & 0 \\
\hline G3 & 0 & 0 & 0 & 0 & 0 \\
\hline \multicolumn{6}{|l|}{ Group B $(n=18)$} \\
\hline G0 & $8(44.4 \%)$ & $11(61.1 \%)$ & $12(66.7 \%)$ & $17(94.4 \%)$ & $18(100 \%)$ \\
\hline G1 & $10(55.6 \%)$ & $7(38.9 \%)$ & $6(33.3 \%)$ & $1(5.6 \%)$ & 0 \\
\hline G2 & 0 & 0 & 0 & 0 & 0 \\
\hline G3 & 0 & 0 & 0 & 0 & 0 \\
\hline \multicolumn{6}{|l|}{ Group C $(n=19)$} \\
\hline G0 & $4(21.1 \%)$ & $8(42.1 \%)$ & $11(57.9 \%)$ & $17(89.5 \%)$ & $19(100 \%)$ \\
\hline G1 & $15(78.9 \%)$ & $11(57.9 \%)$ & $8 \quad(42.1 \%)$ & $2(10.5 \%)$ & 0 \\
\hline G2 & 0 & 0 & 0 & 0 & 0 \\
\hline G3 & 0 & 0 & 0 & 0 & 0 \\
\hline \multirow{5}{*}{$\begin{array}{c}\text { Statistical } \\
\text { significance }\end{array}$} & $\chi^{2}=6.12$ & $\chi^{2}=7.75$ & $\chi^{2}=7.59$ & $\chi^{2}=2.17$ & \\
\hline & $\mathrm{P}=.04 *$ & $\mathrm{P}=.02 *$ & $\mathrm{P}=.02 *$ & $\mathrm{P}=.3$ & \\
\hline & $\mathrm{P} 1=0.5$ & $\mathrm{P} 1=0.14$ & $\mathrm{P} 1=0.03 *$ & $\mathrm{P} 1=0.4$ & \\
\hline & $\mathrm{P} 2=0.02 *$ & $\mathrm{P} 2=0.008 *$ & $\mathrm{P} 2=0.008 *$ & $\mathrm{P} 2=0.2$ & \\
\hline & $\mathrm{P} 3=0.17$ & $\mathrm{P} 3=0.33$ & $\mathrm{P} 3=0.73$ & $\mathrm{P} 3=1$ & \\
\hline
\end{tabular}

$\chi^{2}=$ Chi-Square test $\quad$ statistically significant at $p$ value $<0.05 * p$ value significant

p1: Fisher's exact test value between group A and group B, p2: Fisher's exact test value between group A \& C,p3: Fisher's exact test value between group $B$ \& $C$

TABLE (3): Comparison between the three groups according to healing of extraction socket 7 days postoperatively.

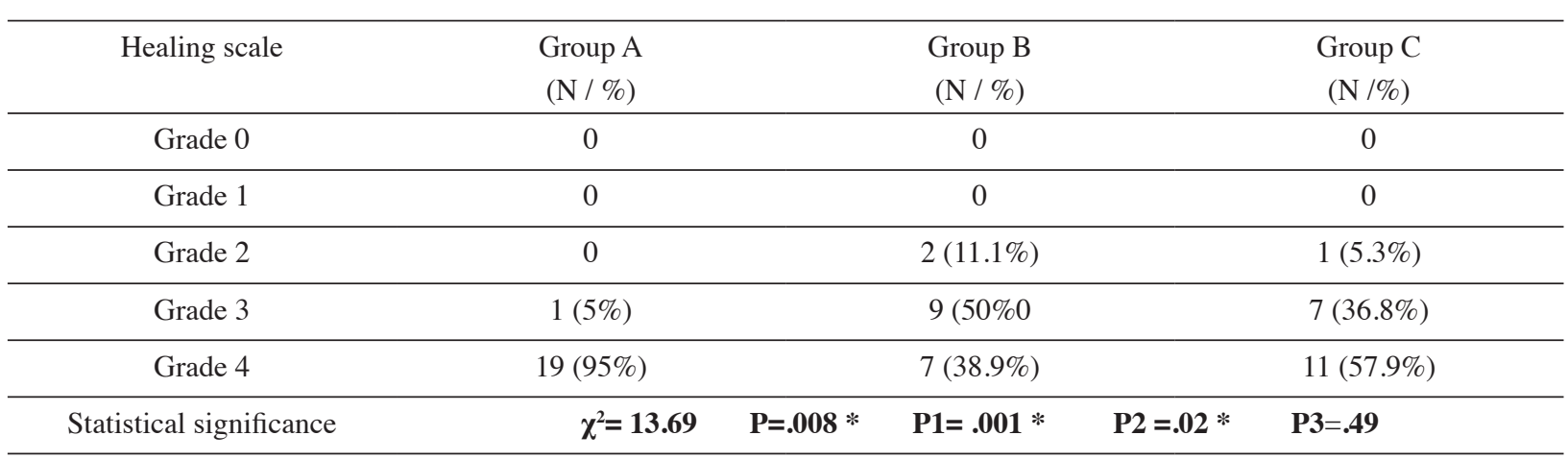

$\chi 2=$ Chi-Square test $\quad * p$ value significant $<0.05$

p1: $p$ value between group $A$ and group $B, p 2: p$ value between group $A \& C, p 3: p$ value between group $B \& C$ 
TABLE (4): Comparison between the three groups according to pain 1 st, 3rd and 7th day postoperatively.

\begin{tabular}{|c|c|c|c|}
\hline \multirow[t]{2}{*}{ Pain scale } & \multicolumn{3}{|c|}{ Post operative pain } \\
\hline & 1 day & 3 days & 7 days \\
\hline \multicolumn{4}{|c|}{ Group A $(n=20)$} \\
\hline G0 & $13(65 \%)$ & $18(90 \%)$ & $20(100 \%)$ \\
\hline G1 & $6(30 \%)$ & 2 (10\%) & 0 \\
\hline G2 & $1 \quad(5 \%)$ & 0 & 0 \\
\hline G3 & 0 & 0 & 0 \\
\hline G4 & 0 & 0 & 0 \\
\hline \multicolumn{4}{|c|}{ Group B $(n=18)$} \\
\hline G0 & $5(27.8 \%)$ & $7(38.9 \%)$ & $18(100 \%)$ \\
\hline G1 & $7(38.9 \%)$ & $8(44.4 \%)$ & 0 \\
\hline G2 & $6(33.3 \%)$ & $3(16.7 \%)$ & 0 \\
\hline G3 & 0 & 0 & 0 \\
\hline G4 & 0 & 0 & 0 \\
\hline \multicolumn{4}{|c|}{ Group C $(n=19)$} \\
\hline G0 & $5(26.3 \%)$ & $13(68.4 \%)$ & $19(100 \%)$ \\
\hline G1 & $10(52.6 \%)$ & $5 \quad(26.3 \%)$ & 0 \\
\hline G2 & $4 \quad(21.1 \%)$ & $1(5.3 \%)$ & 0 \\
\hline G3 & 0 & 0 & 0 \\
\hline G4 & 0 & 0 & 0 \\
\hline \multirow{5}{*}{$\begin{array}{l}\text { Statistical } \\
\text { significance }\end{array}$} & $\chi^{2}=9.88$ & $\chi^{2}=11.87$ & \\
\hline & $P=.04$ * & $P=.018 *$ & \\
\hline & $\mathbf{P} 1=.028 *$ & $P 1=.003 *$ & \\
\hline & P2 $=.04 *$ & $\mathrm{P} 2=.21$ & \\
\hline & $P 3=.64$ & $P 3=.18$ & \\
\hline
\end{tabular}

$\chi^{2}=$ Chi-Square test $\quad * p$ value significant $<0.05$

p1: $P$ value between group $A$ and group $B, p 2: p$ value between group $A \& C, p 3: p$ value between group $B \& C$ G0; no pain-G1; mild pain-G2; moderate pain-G3; sever pain-G4; extreme pain.

\section{3) Post operative Pain}

Table 4 shows the assessed grades of postoperative pain for all patients after 1, 3 and 7 days post extraction. No patient suffered severe or extreme pain after extraction and throughout the follow up. After three days three patients from group (B) and one patient from group (C) recorded moderate pain. After 7 days all patients were free of pain. From this table, it was found that there was a statistically significant association between variables at first and third days postoperatively in favor to PRF ( $\mathrm{p}=.04, .018)$.

\section{DISCUSSION}

Although clinical guidelines regard dental interventions as minor procedures, with low risk of bleeding, patients on anticoagulation therapy are at higher risk of bleeding complications, during and following dental surgeries. ${ }^{(30)}$ The management of these patients is considered a challenge for oral and maxillofacial surgeons.

All patients in this study had undergone dental extraction without modifying their anticoagulation medication regimens, based on the evidence that the benefit of preventing thromboembolism balances the risk of bleeding. Sacco et al ${ }^{(31)}$ revealed that there were no differences between reducing the dose of the oral anticoagulant or maintaining the same dose with the support of local hemostatic measures in patients undergoing oral surgical procedures. Bacci et al ${ }^{(32)}$ have shown that teeth extraction can be performed safely in patients on anticoagulants without any modification of their therapy. Cessation of warfarin preoperatively may invite a fatal risk of thromboembolism. Whal et al ${ }^{(33)}$ informed 22 embolic complications, including 6 fatal events among 2673 patients whose warfarin dose was reduced or withdrawn before dental procedures.

As the current consent recommends continuing of anticoagulant regimen and avoiding hemorrhagic complications by working with therapeutic INR levels and adopting effective local hemostatic 
measures ${ }^{(34)}$, this study was conducted to assess the efficacy of platelet rich fibrin in controlling hemorrhage and improving wound healing after dental extraction in patients on oral anticoagulant therapy.

PRF was the material of choice in this study because of its proposed regenerative properties and its qualification to improve tissue healing that would make it a promising local hemostatic agent after minor surgical procedures. The efficacy of PRF was assessed in this study in comparison to absorbable gelatin sponge and Tranexamic acid as they are clinically available and commonly used topical hemostatics. ${ }^{(35)}$ Tranexamic acid has an antifibrinolytic agent that inhibits both plasminogen activation and plasmin activity. Thus, preventing clot breakdown instead of promoting new clot formation. Other studies have investigated its clinical effect on postoperative bleeding after tooth extraction in patients on anticoagulant treatment. ${ }^{(36)}$ Gel foam is biocompatible, biodegradable, its mode of action is related to formation of a mechanical matrix that facilitates clotting rather than affecting the blood clotting mechanism. ${ }^{(37)}$

By investigating INR level the day before surgery, all patients included in this study had INR less than 3.5 with a mean of 2.36 without significant difference between the three groups, this is in accordance with many studies recommended continuing same dose of warfarin therapy before dental extraction as long as the INR level is maintained $<3.5$ and effective hemostasis is achieved. ${ }^{(9-12)}$

All teeth extractions were done as atraumatic as possible by simple extraction technique by one oral surgeon in order not to affect on postoperative complications. Extraction of teeth with acute or chronic periapical infection were excluded because the predominant granulation tissue associated with chronic infection, combined with other inflammatory signs can contribute to the increased incidence of postoperative bleeding. Morimoto et $\mathbf{a l}^{(38)}$ reported a significantly increased postoperative bleeding associated with surgical extraction and acute inflammation.

Regarding the assessment of immediate postoperative bleeding of all 57 extraction sockets included in this study at different time intervals of follow up, there was a significant difference between groups after 5 minutes $(p=.04), 30$ minutes $(\mathrm{p}=.02)$ and 1 hour after extraction $(\mathrm{p}=.02)$ showing that PRF would efficiently reduce the risk of postoperative bleeding when compared with the other local hemostatic agents.

These results could be attributed to PRF ability to liberate high amounts of growth factors in a slow and prolonged manner, such as platelet-derived growth factor, transforming growth factor and vascular endothelial growth factor, during at least 7 days. It also releases matrix proteins such as thrombospondin-1 which plays a considerable role in the coagulation pathways and clot formation. This key molecule, and certainly many others, obviously contributes to the antihemorrhagic properties of the PRF clot. ${ }^{(39,40)}$ Similarly, Various other studies found that PRF could be utilized for the management of bleeding after extraction of the mandibular third molar ${ }^{(41-44)}$, which is situated in an area often prone to several complications.

Regarding the assessment of delayed postoperative bleeding after 1 day or 3 days; there was no statistically significant association between variables. However, three extraction sockets from group B and $\mathrm{C}$ recorded mild secondary hemorrhage $24 \mathrm{~h}$ postoperatively and was successfully managed by suturing. Growth factors released from PRF, and the strong fibrin construction of the clot accelerate and enhance the healing of soft tissue and bone remodeling. ${ }^{(45,46)}$ As the wound closure is accelerated, delayed bleedings are logically avoided.

The present study also gave superior results for PRF in improving post-operative healing of extraction sockets $(\mathrm{p}=.008)$ with no incidence of infection or dry socket. Foreign materials packed in the extraction sockets tends to disrupt the normal healing 
mechanism, while PRF, due to its autogenic nature, is completely tolerated. Petersen J K ${ }^{(47)}$ reported that gel foam delays recovery in the region of tooth extraction. Moreover, PRF contains supraphysiological concentrations of leukocytes that have a significant role in protecting the surgical sites against local infections and related delayed healing. ${ }^{(48)}$

These results are in accordance with other studies in literature reported the positive effect of PRF on wound healing. Lundquist et al ${ }^{(49)}$ suggested that the PRF could be beneficial for the healing of wounds due to the continued release of PDGF over several days. Sharma et al ${ }^{(50)}$ recorded that PRF is significantly better in promoting soft tissue healing and hastens bone formation in extraction socket. Similarly, Petrescu BN ${ }^{(51)}$ proved the efficacy of PRF as a wound healing accelerator of gingival tissue. In comparison to gelatin sponge, results showed high statistical significant difference ( $\mathrm{p}=.001)$. Similarly, Alhalabi $\mathbf{L}^{(37)}$ noted that gelatin sponge soaked with platelet-rich plasma benefited in enhancing the healing of soft tissues more than gelatin sponge alone.

As regard postoperative pain assessment, it was found that patients who were treated with the PRF showed significant minimal pain when evaluated on subsequent follow ups after 1 and 3 days ( $\mathrm{p}=.04$, .018). This agreed with previous studies; Sarkar et al ${ }^{(52)}$ demonstrated that PRF gel improved wound healing in contrast with Chitosan with less postoperative pain after dental extractions in 60 patients receiving oral anticoagulants. Sammartino et $\mathbf{a l}{ }^{(53)}$ reported that more than $60 \mathrm{PRF}$ clots placed in post extraction sockets succeeded to inhibit pain in the postoperative period.

Statistical analysis revealed significant difference in pain records among PRF and gelatin sponge after 1 and 3 days $(\mathrm{p}=.028, .003)$, this was agreed with Alhalabi L (37) who found that by using gelatin sponge alone, the average pain was slightly bigger than using gelatin sponge soaked with PRF. Also,
Petersen et al ${ }^{(47)}$ found the pain associated with application of gelatin sponge alone in the extraction socket was bigger than the pain when using any material.

In agreement with this study, previous systematic reviews recorded the efficacy of PRF on promoting bone and soft tissue healing ${ }^{(54)}$, pain relief ${ }^{(55-57)}$, and reducing the incidence of alveolar osteitis ${ }^{(58)}$ after tooth extraction.

Results of this study would favor the use of PRF as a local hemostatic measure after dental extraction, this is in concordance with other recent studies; Mourao et al ${ }^{(59)}$ concluded that PRF is a promising hemostatic agent for anticoagulant patients. Similarly, Harfoush et al ${ }^{(60)}$ stated that the local application of PRF was more effective as a hemostatic agent than suturing and gauze compression after tooth extractions in patients using warfarin. Eldibany RM ${ }^{(61)}$ reported complete hemostasis, minimum postoperative pain, and a faster healing process by using PRF versus Hemcon dental dressing in patients receiving anticoagulant therapy.

In contrast to results of this study, Sarkar et al ${ }^{(52)}$ concluded that the application of PRF had a longer bleeding time in anticoagulated patients when compared to chitosan hydrogel after dental extractions. They explained that by the electropositive nature of chitosan which led to a clot formation based on electrostatic charge attraction and not by enhancing clotting factors. Another study found no significant difference between PRF and tranexamic acid in controlling hemorrhage after dental extraction. However, in contrast to our study, they repeated the dressing of $4.8 \%$ tranexamic acid after each hour for 24 hours, additionally they used mouth wash of $4.8 \%$ tranexamic acid three times a day for 3 days post extraction. ${ }^{(62)}$

In conclusion, this study supports the current consent of continuing the regimen of anticoagulant therapy, within the therapeutic range of INR, and avoiding hemorrhagic complications by using effective local measures. The limitations of the 
present research are correlated to the small number of studied patients and absence of a negative control group. Ethical considerations did not allow us to evaluate the risk of bleeding without therapeutic intervention.

However, results of this study could validate the efficacy of PRF in the prevention of postoperative bleeding after dental extractions in patients on anticoagulant therapy. Although other procedures can lead to similar results; PRF is autogenous, easily applied, minimally invasive, repeatable, low cost, and a complication avoiding procedure. The advantages of PRF are not only related to its antihemorrhagic properties, but also its capability to accelerate wound closure, decrease postoperative pain and guard the extraction sockets against unavoidable infections.

\section{CONCLUSION}

This study supports the concept that dental extractions can be carried out safely for patients on oral anticoagulant therapy, with the aid of local hemostatic agents as long as INR level is maintained within the therapeutic range.

The results of this study concluded that PRF has significant antihemorrhagic properties. It enhances tissue healing and wound closure, minimizes postoperative pain, and decreases the risk of infection. PRF could a promising autogenous, low cost, local hemostatic modality that can be used safely after dental extraction for patients under anticoagulant therapy. However, long-term studies with greater sample size are needed for further conclusive results.

\section{REFERENCES}

1. Wahl MJ. Myths of dental surgery in patients receiving anticoagulant therapy. J Am Dent Assoc. 2000; 131:77-81.

2. Bajkin BV, Urosevic IM, Stankov KM, Petrovic BB, Bajkin IA. Dental extractions and risk of bleeding in patients taking single and dual antiplatelet treatment. Br J Oral Maxillofac Surg. 2015; 53(1): 39-43.
3. Dudek D, Kuliczkowski W, Kaczmarski J, Wiechec J, Reichman-Warmusz E, Segiet O, Helewski K, Wojnicz R, \& Serebruany V. L. Response to dual antiplatelet therapy does not impact bleeding risks in patients undergoing oral surgery after acute coronary syndromes. Cardiology. 2015; 132(2):119-123.

4. Aframian, DJ, Lalla RV, Peterson DE. Management of dental patients taking common hemostasis-altering medications. Oral Surg Oral Med Oral Pathol Oral Radiol Endod. 2007;103: S45-S11.

5. Karsli ED, Erdogan O, Esen E, Acarturk E. Comparison of the effects of warfarin and heparin on bleeding caused by dental extraction: a clinical study. J Oral Maxillofac Surg. 2011; 69:2500-2507.

6. Evans IL, Sayers MS, Gibbons AJ, Price G, Snooks H, Sugar AW. Can warfarin be continued during dental extraction? Results of a randomized controlled trial. Br J Oral Maxillofac Surg. 2002; 40:248-52.

7. Hirsh J, Fuster V, Ansell J, Halperin JL. American Heart Association/American College of Cardiology foundation guide to warfarin therapy. J Am Coll Cardiol. 2003; 41:1633-52.

8. Salam S, Yusuf H, Milosevic A. Bleeding after dental extractions in patients taking warfarin. Br J Oral Maxillofac Surg. 2007; 45:463-466.

9. Nematullah A, Alabousi A, Blanas N, et al. Dental surgery for patients on anticoagulant therapy with warfarin: a systematic review and meta-analysis. Tex Dent J. 2009; 126:1183-1193.

10. Randall C. Surgical management of the primary care dental patient on warfarin. Dent Update. 2005; 32:414-420.

11. Bajkin BV, Popovic SL, Selakovic SD. Randomized, prospective trial comparing bridging therapy using lowmolecular-weight heparin with maintenance of oral anticoagulation during extraction of teeth. J Oral Maxillofac Surg 2009; 67(5): 990-5.

12. Rodríguez-Cabrera MA, Barona-Dorado C, Leco-Berrocal I, Gómez- Moreno G, Martínez-González JM. Extractions without eliminating anticoagulant treatment: A literature review. Med Oral Patol Oral Cir Bucal 2011; 16(6): 800-4.

13. Al-Mubarak S, Al-Ali N, Abou-Rass M. Evaluation of dental extractions, suturing and INR on postoperative bleeding of patients maintained on oral anticoagulant therapy. Br Dent J. 2007; 203(7):E15. 
14. Carter G, Goss A. Tranexamic acid mouthwash: A prospective randomized study of a 2-day regimen vs 5-day regimen to prevent postoperative bleeding in anticoagulated patients requiring dental extractions. Int J Oral Maxillofac Surg 2003; 32(5): 504-7.

15. Elshiha H, Tawfic H, Abousamra N \& Marzouk H. Efficacy of chitosan and absorbable gelatin sponge on hemostasis and wound healing following tooth extraction "a comparative study". Egyptian dental journal. 2012; 58: 2443-2447.

16. Al-Belasy FA, Amer MZ. Hemostatic effect of n-butyl-2cyanoacrylate (histoacryl) glue in warfarin-treated patients undergoing oral surgery. J Oral Maxillofac Surg 2003; 61(12): 1405-9.

17. Bajkin B, Selakovic S, Mirkovic S, Sarcev I, Tadic A, \& Milekic B. Comparison of efficacy of local hemostatic modalities in anticoagulated patients undergoing tooth extractions. Military Medical and Pharmaceutical Journal of Serbia. 2014; 71(12): 1097-1101.

18. Choukroun J, Diss A, Simonpieri A, Girard MO, Schoeffler C, Dohan SL, Dohan AJ, Mouhyi J, Dohan DM. Plateletrich fibrin (PRF): a second-generation platelet concentrate. Part IV: clinical effects on tissue healing. Oral Surg Oral Med Oral Pathol Oral Radiol Endod. 2006;101(3):e56-60.

19. Dias FJ, Venegas C, Borie E, Arias A, Watanabe IS, Fuentes R. A new insight of Platelet-Rich Fibrin clots morphology and their elemental composition. Tissue Cell. 2020 Aug; 65:101362.

20. Fan Y, Perez K, Dym H. Clinical Uses of Platelet-Rich Fibrin in Oral and Maxillofacial Surgery. Dent Clin North Am. 2020; 64(2):291-303.

21. Ivanova V, Chenchev I, Zlatev S, Mijiritsky E. Comparison Study of the Histomorphometric Results after Socket Preservation with PRF and Allograft Used for Socket Preservation-Randomized Controlled Trials. Int J Environ Res Public Health. 2021 Jul 13;18(14):7451.

22. Irdem HO, Dolanmaz D, Esen A, Ünlükal N, Şimsek S. Evaluation of the Effectiveness of Liquid Platelet-Rich Fibrin and Deproteinized Bovine Bone Mineral Mixture on Newly Formed Bone in Maxillary Sinus Augmentation: A Split-Mouth, Histomorphometric Study. Niger J Clin Pract. 2021; 24(9):1366-1372.

23. Gusman DJR, Matheus HR, Alves BES, de Oliveira AMP, Britto ACS, Novaes VCN, Nagata MJH, Batista VES, de Almeida JM. Platelet-rich fibrin for wound healing of palatal donor sites of free gingival grafts: Systematic review and meta-analysis. J Clin Exp Dent. 2021;13(2):190-200

24. Ragab H, Melek L. Comparison of two hemostatic agents in patients receiving anticoagulants without altering medication dosage. Egyptian Dental Journal. 2019;65: 33153321.

25. Walid Ahmed Abdullah, Hesham Khalil. Dental extraction in patients on warfarin treatment. Clinical, Cosmetic and Investigational Dentistry 2014:6 65-69.

26. Nishimura RA, Otto CM, Bonow RO, Carabello BA, Erwin JP 3rd, Fleisher LA, Jneid H, Mack MJ, McLeod CJ, O'Gara PT, Rigolin VH, Sundt TM 3rd, Thompson A. 2017 AHA/ACC Focused Update of the 2014 AHA/ACC Guideline for the Management of Patients With Valvular Heart Disease: A Report of the American College of Cardiology/American Heart Association Task Force on Clinical Practice Guidelines. Circulation. 2017; 20;135(25): e1159e1195.

27. Maani S SM, Melek L, Sadaka M. Evaluation Of Colloidal Silver Gelatin Sponge (Gelatamp) In Patients Receiving Anticoagulant After Tooth Extraction (Clinical Study). Alexandria Dental Journal. 2015; 40:101-6.

28. Ishihama Kohji, Tetsuo Kimura, Yasunobu Yasui, Masashikomaki, Yukihiro Ota. Azithromycin as prophylaxis for the prevention of postoperative infection in impacted Mandibular thitd-molar Surgery. J infect Chemother. 2006,12:31-35.

29. Bendinger T, Plunkett N. (2016). Measurement in pain medicine. BJA Education,2016; 16(9), 310-315.

30. De Campos N, Furlaneto F, De Paiva Buischi Y. Bleeding in Dental Surgery 2019. Doi;10.5772/intechopen.89992.

31. Sacco R, Sacco M, Carpenedo M, Mannucci PM. Oral surgery in patients on oral anticoagulant therapy: a randomized comparison of different intensity targets. Oral Surg Oral Med Oral Pathol Oral Radiol Endod 2007; 104: E18e21

32. Bacci C, Maglione M, Favero L, et al. Management of dental extraction in patients undergoing anticoagulant treatment. Results from a large, multicentre, prospective, case-control study. Thromb Haemost. 2010;104: 972-975.

33. Wahl MJ, Pinto A, Kilham J, Lalla RV. Dental surgery in anticoagulated patients-stop the interruption. Oral Surg Oral Med Oral Pathol Oral Radiol 2015; 119:136e57.

34. Jim_enez Y, Poveda R, Gavald_a C, Margaix M, Sarri_on G. An update on the management of anticoagulated pa- 
tients programmed for dental extractions and surgery. Med Oral Patol Oral Cir Bucal 2008;13: E176e9.

35. Blinder D, Manor Y, Martinowitz U and Taicher S. Dental extractions in patients maintained on oral anticoagulant therapy: Comparison of INR value with occurrence of postoperative bleeding. International journal of oral and maxillofacial surgery $2001 ; 6: 518-521$.

36. Perry DJ, Noakes TJ, Helliwell PS (2007) Guidelines for the management of patients on oral anticoagulants requiring dental surgery. Br Dent J 203(7): 389-393.

37. Alhalabi L. The effect of gelatin sponge with platelet-rich plasma on pain and soft tissue healing after extraction. Ann Dent Oral Health. 2019; 2(1): 1009.

38. Morimoto Y, Niwa H, Minematsu K. Risk factors affecting postoperative hemorrhage after tooth extraction in patients receiving oral antithrombotic therapy. J Oral Maxillofac Surg. 2011; 69:155-6.

39. Dohan Ehrenfest DM, de Peppo GM, Doglioli P, Sammartino G. Slow release of growth factors and thrombospondin-1 in Choukroun's platelet-rich fibrin (PRF): a gold standard to achieve for all surgical platelet concentrates technologies. Growth Factors. 2009;27: 63-69.

40. Dohan Ehrenfest DM. How to optimize the preparation of leukocyte- and platelet-rich fibrin (L-PRF, Choukroun's technique) clots and membranes: introducing the PRF Box. Oral Surg Oral Med Oral Pathol Oral Radiol Endod. 2010;110: 275-278; author reply 278-280.

41. Hoaglin DR, Lines GK. Prevention of localized osteitis in mandibular third- molar sites using platelet-rich fibrin. Int J Dent 2013:875380

42. Eshghpour M, Danaeifar N, Kermani H, Nejat AH. Does intra-alveolar application of chlorhexidine gel in combination with platelet-rich fibrin have an advantage over application of plateletrich fibrin in decreasing alveolar osteitis after mandibular third molar surgery? A double-blinded randomized clinical trial. J Oral Maxillofac Surg 2018; 76:939.e1-939.e7

43. Daugela P, Grimuta V, Sakavicius D, Jonaitis J, Juodzbalys G. Influence of leukocyte- and platelet-rich fibrin (L-PRF) on the outcomes of impacted mandibular third molar removal surgery: a split-mouth randomized clinical trial. Quintessence Int 2018; 49:377-388

44. Jeyaraj PE, Chakranarayan A. Soft tissue healing and bony regeneration of impactedmandibular thirdmolar extraction sockets, following postoperative incorporation of plateletrich fibrin. Ann Maxillofac Surg 2018; 8:10-18

45. Clark RA. Fibrin and wound healing. Ann N Y. Acad Sci. 2001; 936: 355-367.

46. Dohan Ehrenfest DM, Diss A, Odin G, Doglioli P, Hippolyte MP, Charrier JB. In vitro effects of Choukroun's PRF (platelet-rich fibrin) on human gingival fibroblasts, dermal prekeratinocytes, preadipocytes and maxillofacial osteoblasts in primary cultures. Oral Surg Oral Med Oral Pathol Oral Radiol Endod. 2009;108:341-352.

47. Petersen JK, Krogsgaard J, Nielsen KM, et al. A comparison between 2 absorbable hemostatic agents: gelatin sponge (Spongostan) and oxidized regenerated cellulose (Surgicel) Int J Oral Surg. 1984; 13: 406-410.

48. Dohan Ehrenfest DM, Rasmusson L, Albrektsson T. Classification of platelet concentrates: from pure platelet-rich plasma (P-PRP) to leucocyte- and platelet rich fibrin (LPRF). Trends Biotechnol. 2009; 27:158-167.

49. Lundquist R, Holmstrøm K, Clausen C, Jørgensen B, Karlsmark T. Characteristics of an autologous leukocyte and platelet-rich fibrin patch intended for the treatment of recalcitrant wounds. Wound Repair Regen 2013; 21: 66e76.

50. Sharma A, Ingole S, Deshpande M, Ranadive P, Sharma S, Kazi N, Rajurkar S. Influence of platelet-rich fibrin on wound healing and bone regeneration after tooth extraction: A clinical and radiographic study. J Oral Biol Craniofac Res. 2020;10(4):385-390.

51. Petrescu BN, Mirica IC, Miron R, Campian RS, Lucaciu O. Platelet rich fibrin as a gingival tissue regeneration enhancer. J Dent Sci. 2021; 16(1):536-539.

52. Sarkar S, Prashanth NT, Shobha ES, Rangan V, Nikhila G: Efficacy of platelet rich fibrin versus chitosan as a hemostatic agent following dental extraction in patients on antiplatelet therapy. J Oral Biol Craniofac Res 2019; 9:336-339.

53. Sammartino G, Dohan Ehrenfest DM, Carile F, Tia M, Bucci P. Prevention of hemorrhagic complications after dental extractions into open heart surgery patients under anticoagulant therapy: the use of leukocyte- and plateletrich fibrin. J Oral Implantol 2011; 37:681-690.

54. Del Fabbro M, Bucchi C, Lolato A, Corbella S, Testori T, Taschieri S. Healing of postextraction sockets preserved with autologous platelet concentrates. A systematic review and meta-analysis. J Oral Maxillofac Surg 2017; 75:1601-1615 
55. Miyamoto H, Nakamura T, Takashima H, Mizutani $T$, Morita M, Hirose M, Kurata M, Maeda M, Aoki N, Kato S, Shibuya Y. Investigation of the analgesic effect of plateletrich fibrin on postoperative pain after mandibular impacted wisdom tooth extraction. Journal of Oral and Maxillofacial Surgery, Medicine, and Pathology. 2020; 32: 237-240.

56. He Y, Chen J, Huang Y, Pan Q, Nie M. Local application of platelet rich fibrin during lower third molar extraction improves treatment outcomes. J Oral Maxillofac Surg 2017; 75:2497-2506

57. Bao M, Du G, Zhang Y, Ma P, Cao Y, Li C. Application of Platelet-Rich Fibrin Derivatives for Mandibular Third Molar Extraction Related Post-Operative Sequelae: A Systematic Review and Network Meta-Analysis. J Oral Maxillofac Surg. 2021; 13:S0278-2391.

58. Zhu J, Zhang S, Yuan X, He T, Liu H, Wang J, Xu B. Effect of platelet-rich fibrin on the control of alveolar osteitis, pain, trismus, soft tissue healing, and swelling following mandibular third molar surgery: an updated systematic re- view and meta-analysis. Int J Oral Maxillofac Surg. 2021; 50(3):398-406.

59. Mourao CF, Miron RJ, de Mello Machado RC, Ghanaati S, Alves GG, Calasans-Maia MD: Usefulness of plateletrich fibrin as a hemostatic agent after dental extractions in patients receiving anticoagulant therapy with factor Xa inhibitors: a case series. Oral Maxillofac Surg 2019; 23:381-386.

60. Harfoush M, Boutros E, Al-Nashar A. Evaluation of topical application of platelet rich fibrin (PRF) in homeostasis of the bleeding after teeth extraction in patients taking warfarin. Int Dental J Stud Res 2016; 4:144-147.

61. Eldibany RM: Platelet rich fibrin versus Hemcon dental dressing following dental extraction in patients under anticoagulant therapy. Tanta Dental J 2014; 11:75-84.

62. Munawar DL, Syed GH, Sajid M, Wajid AR, Waq AS, Babar A, Salman S. Hemostatic Effect of Platelet Rich Fibrin Versus Tranexamic Acid After Tooth Extraction in Patients Under Anticoagulant Therapy. OAJBS. 2020; 2: 404-407. 